\title{
Elevated baseline C-reactive protein levels predict poor progression-free survival in sporadic vestibular schwannoma
}

\author{
Johannes Wach ${ }^{1}$ (1) - Ági Güresir ${ }^{1}$ - Valeri Borger ${ }^{1} \cdot$ Patrick Schuss ${ }^{1}$ - Albert Becker ${ }^{2}$. Christoph Coch $^{3}$. \\ Marie-Therese Schmitz ${ }^{4} \cdot$ Michael Hölzel $^{5} \cdot$ Marieta Toma $^{6} \cdot$ Ulrich Herrlinger $^{7} \cdot$ Hartmut Vatter $^{1} \cdot$ Erdem Güresir $^{1}$
}

Received: 5 November 2021 / Accepted: 1 December 2021 / Published online: 9 December 2021

(c) The Author(s) 2021

\begin{abstract}
Background Recent investigations showed emerging evidence of the role of inflammation in the growth of sporadic vestibular schwannoma (VS). The present retrospective study investigated the impact of systemic inflammation on tumor progression using serum C-reactive protein (CRP) levels in a series of 87 surgically treated sporadic VS patients.

Methods The optimal cut-off value for CRP was defined as $3.14 \mathrm{mg} / \mathrm{dl}$ according to the receiver operating characteristic curve (AUC: $0.70,95 \%$ CI $0.47-0.92)$. Patient cohort was dichotomized into normal $(\mathrm{n}=66 ;<3.14 \mathrm{mg} / \mathrm{dl}$ ) and high baseline $(\mathrm{n}=21 ; \geq 3.14 \mathrm{mg} / \mathrm{dl})$ CRP groups.

Results No significant differences in age, sex, comorbidities influencing the systemic inflammatory state, Karnofsky performance status (KPS), tumor size, extent of resection, or MIB-1 index were identified between the two groups defined by the baseline CRP levels. Univariable analysis demonstrated that a high CRP level $(\geq 3.14 \mathrm{mg} / \mathrm{dl})$ is significantly associated with a shortened progression-free survival (PFS) (hazard ratio (HR): 6.05, 95\% CI 1.15-31.95, $p=0.03$ ). Multivariable Cox regression analysis considering age, extent of resection, KPS, tumor size, and baseline CRP confirmed that an elevated CRP level $(\geq 3.14 \mathrm{mg} / \mathrm{dl}$ ) is an independent predictor of shortened PFS (HR: 7.20, 95\% CI 1.08-48.14, $p=0.04$ ).

Conclusions The baseline CRP level thus serves as an independent predictor of PFS. Further investigations of the role of inflammation and tumor inflammatory microenvironment in the prediction of prognosis in sporadic VS are needed.
\end{abstract}

Johannes Wach

Johannes.wach@ukbonn.de

1 Department of Neurosurgery, Rheinische Friedrich-

Wilhelms-University, Venusberg-Campus 1, Bonn, Germany

2 Department of Neuropathology, Rheinische Friedrich-Wilhel ms-University, Bonn, Germany

3 Institute of Clinical Chemistry and Clinical Pharmacology, Rheinische Friedrich-Wilhelms-University, Bonn, Germany

4 Department of Medical Biometry, Informatics and Epidemiology, Rheinische Friedrich-Wilhelms-Universi ty, Bonn, Germany

5 Institute of Experimental Oncology, Rheinische Friedrich-Wi lhelms-University, Bonn, Germany

6 Institute of Pathology, Rheinische Friedrich-Wilhelms-Unive rsity, Bonn, Germany

7 Division of Clinical Neurooncology, Department of Neurology and Centre of Integrated Oncology, Rheinische Friedrich-Wilhelms-University, Bonn, Germany 


\section{Graphical abstract}

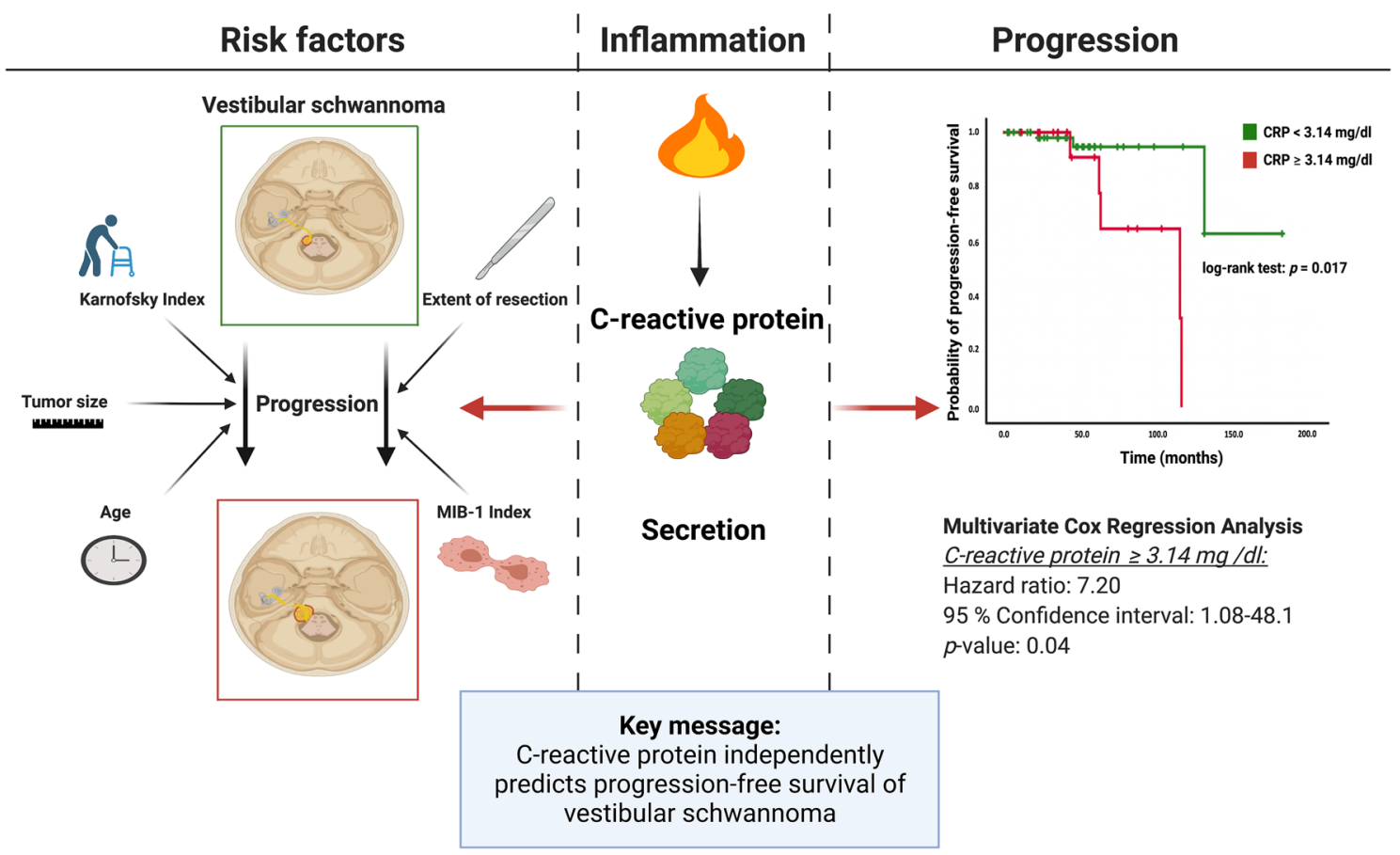

Keywords C-reactive protein · Inflammation · Progression · Vestibular schwannoma

$\begin{array}{ll}\text { Abbreviations } \\ \text { AUC } & \begin{array}{l}\text { Area under the receiver-operating characteristic } \\ \text { curve }\end{array} \\ \text { CD } & \text { Cluster of differentiation } \\ \text { CI } & \text { Confidence interval } \\ \text { COX-2 } & \text { Cyclooxygenase-2 } \\ \text { CRP } & \text { C-reactive protein } \\ \text { CSF } & \text { Cerebrospinal fluid } \\ \text { DCE } & \text { Dynamic contrast-enhanced } \\ \text { GTR } & \text { Gross total resection } \\ \text { HR } & \text { Hazard ratio } \\ \text { KPS } & \text { Karnofsky performance status } \\ \text { MIB } & \text { Molecular immunology borstel } \\ \text { MRI } & \text { Magnetic resonance imaging } \\ \text { PD-L1 } & \text { Programmed cell death 1 ligand 1 } \\ \text { PFS } & \text { Progression-free survival } \\ \text { ROC } & \text { Receiver-operating characteristic (ROC) } \\ \text { STR } & \text { Subtotal resection } \\ \text { TAM } & \text { Tumor-associated macrophage } \\ \text { VS } & \text { Vestibular schwannoma }\end{array}$

\section{Introduction}

Vestibular schwannoma (VS) is a benign tumor that accounts for $75 \%$ of all lesions in the cerebellopontine angle, and it originates from the Schwann cells covering the eighth cranial nerve [1].

It has been suggested that complete resection is the optimal treatment to achieve long-term tumor control in giant VS [2]. However, data also suggest that subtotal resection with subsequent irradiation of tumor remnants, if necessary, is also a feasible strategy to achieve a nearly similar results regarding progression-free survival (PFS) [3, 4]. Furthermore, systematic reviews have confirmed that stereotactic radiosurgery achieves sufficient long-term tumor control and hearing preservation for newly diagnosed small VS [5]. In general, a stringent imaging follow-up using magnetic resonance imaging (MRI) of residual tumor tissues is recommended for at least 7-10 years [6].

Systemic inflammation is known to be associated with shortened time to tumor progression in patients with cancer [7, 8]. Recent investigations emphasized the role of inflammation in the growth of VS and the functional outcome following surgery for VS [9-11]. Furthermore, it was discovered that cyclooxygenase-2 (COX-2) expression in VS is significantly associated with tumor 
proliferation and cell growth both in human tumor and in vitro $[12,13]$. To date, despite its paramount importance for optimizing patients' therapy and functional outcome following surgery, no predictive factors for VS growth have been identified $[14,15]$.

C-reactive protein (CRP) is an inflammation-related prognostic biomarker that can predict tumor recurrence and treatment response in adult solid tumors [16]. However, the predictive value of systemic inflammation based on CRP in VS is unknown so far. The purpose of the present study was to assess the relationship between baseline serum CRP levels at initial diagnosis and progressionfree survival in a homogenous population of sporadic VS patients who underwent surgical resection via the retrosigmoid approach without postoperative adjuvant radiation therapies.

\section{Materials and methods}

\section{Study design}

We retrospectively reviewed 140 VS patients from April 2001 to August 2020. Patients with prior radiotherapy, surgery for recurrent VS, stereotactic radiosurgery after resection, neurofibromatosis type 2, lack of imaging follow-up data ( $\geq 3$ months), and lack of baseline CRP levels data were excluded. Figure 1 illustrates the patient selection process, which identified 87 eligible patients. Treatment decision making was based on a multidisciplinary consensus between radiotherapists, otolaryngologists, neuro-oncologists, and neurosurgeons. In the decisionmaking process, the tumor size, its growth rate, the probability of gross total or near total resection with preservation of hearing and facial nerve function, the patient's age, patient's comorbidities, and the patient preferences were considered. Primary radiosurgery or stereotactic radiotherapy was applied for small VSs $(<25 \mathrm{~mm}$ in diameter) with an observed tumor growth in the wait-and-scan policy in patients having functional hearing. However, for larger VSs ( $\geq 25 \mathrm{~mm}$ in diameter) with an observed tumor growth in the wait-and-scan policy, VS patients with symptoms of brainstem compression, young ( $<70$ years) VS $(\geq 25 \mathrm{~mm})$ patients with functional hearing loss or functional hearing ability, small VSs $(<25 \mathrm{~mm})$ with an observed tumor growth in patients with a functional hearing loss, and VS patients with occlusive hydrocephalus, we recommend a surgical resection. Primary radiosurgery or stereotactic radiotherapy for tumors with a diameter greater than $25 \mathrm{~mm}$ can be problematic due to the potential development of a perilesional edema [17]. This decision algorithm is also supported by several guidelines [18].

\section{Biochemical measurements}

Venous blood samples [examination profile: complete blood count, kidney, liver tests, and the coagulation profile (INR, aPTT)] were routinely collected within $24 \mathrm{~h}$ prior to the surgery and data acquisition was performed using Lauris (version 17.06.21, Swisslab GmbH, Berlin, Germany). These laboratory measurements were performed at constant time points, which made it possible to homogeneously analyze time-to-tumor progression. The serum CRP values were obtained by turbidimetric immunoassays with a CRPL3 reagent (Roche, Basel, Switzerland) displaying standard CRP levels. High-sensitivity CRP levels were not included to ensure a homogeneous analysis.

\section{Surgical technique}

All patients underwent tumor resection using the retrosigmoid approach. Surgery was performed in the same workflow as previously reported [11].

\section{Immunohistochemistry}

Surgical specimens were routinely evaluated with haematoxylin/eosin staining and processed for immunohistochemical reactions with antibodies directed against: S-100 (DAKO, Glastrop, Denmark), Ki-67 (MIB1; DAKO, Glastrop, Denmark), and cluster of differentiation (CD) 68 (Clone KP1, dilution 1:1000, DAKO, Glastrop, Denmark). The MIB-1 index was determined in randomly selected high-power microscopic fields in $83(83 / 87 ; 95.4 \%)$ patients. The proportions of stained and unstained nuclei in the tumor cells were determined. The MIB-1 index was defined as the percentage of Ki- $67^{+}$nuclei. Macrophage infiltrates were investigated using CD68 staining.

\section{Data recording and analysis}

The following general preoperative patient characteristics were recorded: age, sex, Karnofsky performance status (KPS), and tumor size.

\section{Tumor size}

Tumor size was categorized according to the largest extrameatal tumor diameter in the cerebellopontine angle on post-contrast axial T1-weighted MR images. The tumor size in term of the diameter was defined as follows: class $3,>4 \mathrm{~cm}$; class 2, 2-4 cm; and class, $1<2 \mathrm{~cm}[11,19]$. 


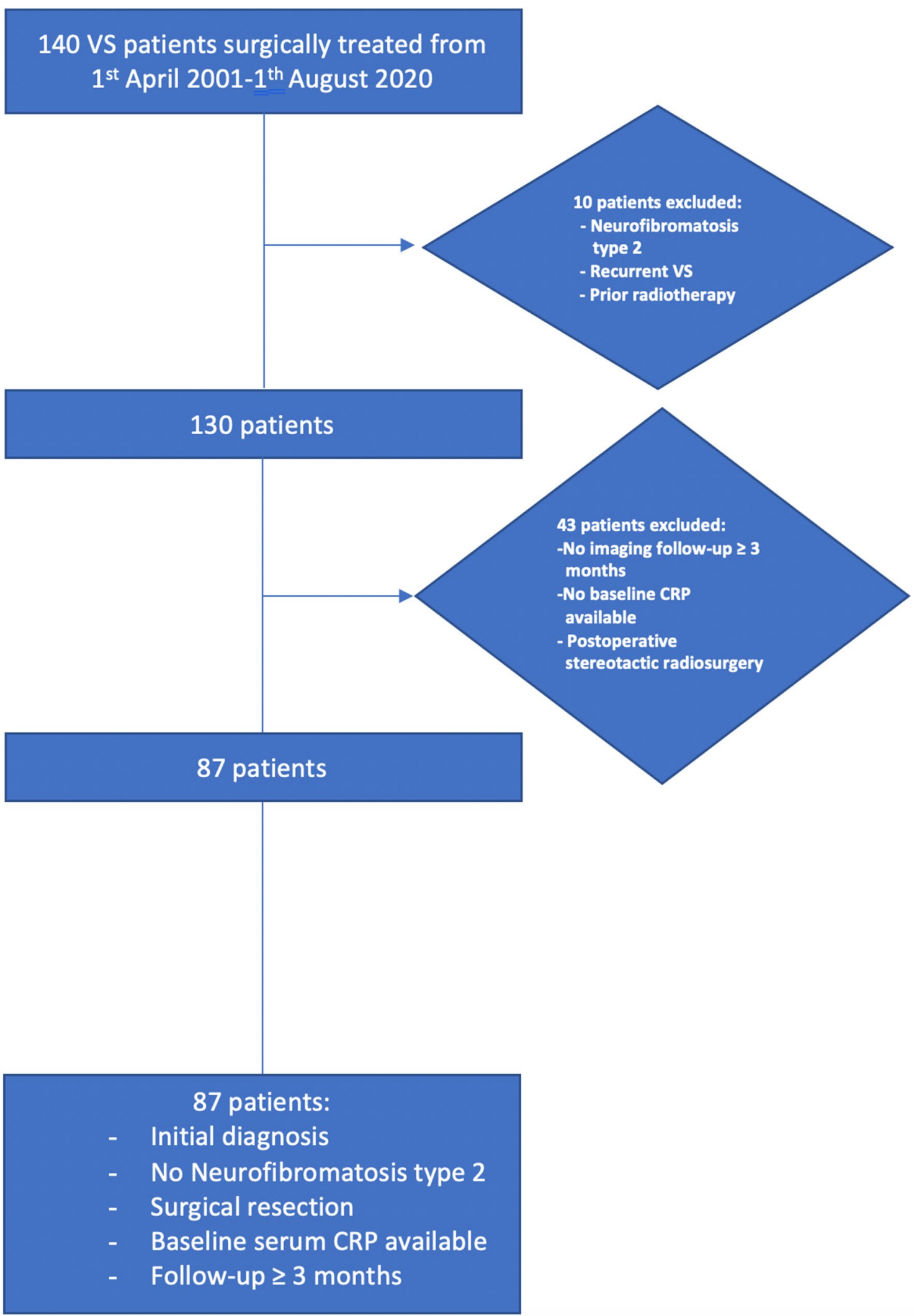

Fig. 1 Flow chart illustrating the selection process of consecutive vestibular schwannoma patients between 2001 and 2020 


\section{Extent of resection}

GTR was defined as complete resection without any residual nodular enhancement, whereas STR was defined as an extent of resection of $90-99 \%$ of the tumor $[11,20]$. The extent of resection was assessed by independent neuroradiologists using pre- and postoperative 1.5 or 3.0 Tesla MR images. First, follow-up MR images were performed three months after surgery and further examinations were executed on an annual basis.

\section{Tumor progression}

Tumor progression was defined as a tumor growth with an increase of $>20 \%$ over the previous tumor volume or a size $2 \mathrm{~mm}$ larger than that found on the previous MRI and the intention to treat the tumor $[11,21,22]$.

\section{Statistics}

Data were analyzed using SPSS@ version 27.0 (IBM Corp, Armonk, New York, USA). Receiver-operating characteristic (ROC) curves were constructed and the area under the receiver-operating characteristic curve (AUC) for CRP in the prediction of VS progression was determined. Furthermore, optimal cutoff point of CRP for dichotomization of this continuous variable was defined using the minimum $p$-value approach, which displays the log-rank test results regarding PFS [23]. Time-dependent ROC curve was created to evaluate the predictive value of serum CRP for PFS after 5-, and 10 years using the R software v4.0.4 (R Foundation for Statistical Computing, Vienna, Austria) and the $\mathrm{R}$ package "risksetROC" [24]. Frequency distribution histogram of serum CRP values was also created. Univariable analyses of the proportions of categorical data among the CRP groups were performed using Fisher's exact test (twosided). A $p$-value $<0.05$ was defined as statistically significant. Furthermore, a uni- and multivariable Cox regression analysis of PFS was performed. Age, KPS, and Tumor size were included in the multivariable Cox regression analysis because those items are potential confounding variables and might be related to extent of resection.

\section{Results}

\section{Patient characteristics}

A total of 87 consecutive VS patients were analyzed. Mean age $( \pm$ Standard deviation $[S D])$ was $53.6( \pm 15.1)$ years and there was a female predominance (female:male $=1.18: 1$ ). Fifteen (17.2\%), 63 (72.5\%), and $9(10.3 \%)$ patients had a tumor defined as tumor size class 1,2 , and 3 , respectively.
The median (25th-75th percentile) KPS was 90.0 (80-90). Gross total resection (GTR) was achieved in $58(66.7 \%)$ patients, whereas subtotal resection (STR) was performed in $29(33.3 \%)$ patients. The mean $( \pm$ SD) Molecular Immunology Borstel (MIB)-1 index was 4.18 ( \pm 1.35$)$.

\section{CRP and cut-off determination}

The mean (range) of baseline serum CRP levels was $3.31 \mathrm{mg} / \mathrm{dl}$ (0.2-64.7). A ROC curve was constructed to determine a CRP cut-off value in the prediction of tumor progression. The AUC of baseline serum CRP for tumor progression was 0.70 (95\% Confidence interval (CI) 0.47-0.92; Youden index: 0.44; Fig. 2A). Sensitivity and specificity of baseline CRP level for predicting recurrence was $63 \%$ and $81 \%$, respectively, with a threshold of $\geq 3.14 \mathrm{mg} / \mathrm{dl}$. Timedependent AUCs of baseline serum CRP for 5-year, and 10 -year PFS were 0.70 and 0.69 , respectively. The C-index was 0.63 (95\% CI 0.52-0.80) and indicates the probability that the baseline serum CRP value in a patient with a shorter time to tumor progression after surgery is higher compared to subjects with no or longer time to progression. Furthermore, patients were dichotomized into normal $(<3.14 \mathrm{mg}$ ) dl) and high ( $\geq 3.14 \mathrm{mg} / \mathrm{dl}) \mathrm{CRP}$ groups according to the most significant split in the log-rank test ( $p=0.017)$ regarding PFS (Supplementary Table 1). Figure 2B displays the optimal cut-point (red line) and the corresponding frequency distribution histogram for serum CRP levels in the cohort. Both methods revealed the same optimal CRP cut-point $(</ \geq 3.14 \mathrm{mg} / \mathrm{dl})$.

\section{Patient characteristics of CRP groups}

The patient cohort was dichotomized into patients with normal $(<3.14 \mathrm{mg} / \mathrm{dl})$ and high $(\geq 3.14 \mathrm{mg} / \mathrm{dl})$ baseline CRP levels. Sixty-six $(75.9 \%)$ patients were allocated to the "normal" CRP group and 21 (24.1\%) to the "high" CRP group. Univariable analyses using the Fisher's exact test (twosided) were performed regarding distribution of sex (female/ male), age $(<60 / \geq 60)$, KPS $(<90 / \geq 90)$, tumor size class $(<4 \mathrm{~cm} / \geq 4 \mathrm{~cm})$, extent of resection (GTR/STR), and the MIB-1 index $(<5 \% / \geq 5 \%)$. Patients were also screened for underlying conditions which could induce chronic inflammation and influence serum CRP levels. The incidence of smoking, obesity, diabetes mellitus and connective tissue diseases were homogeneously distributed in both arms. Patients with blood-borne infectious diseases (e.g., HIV, Hepatitis B, C) or with a malignant cancer were not present in both groups. Potential confounding variables were homogeneously distributed among the CRP groups. Further details are summarized in Table 1. 


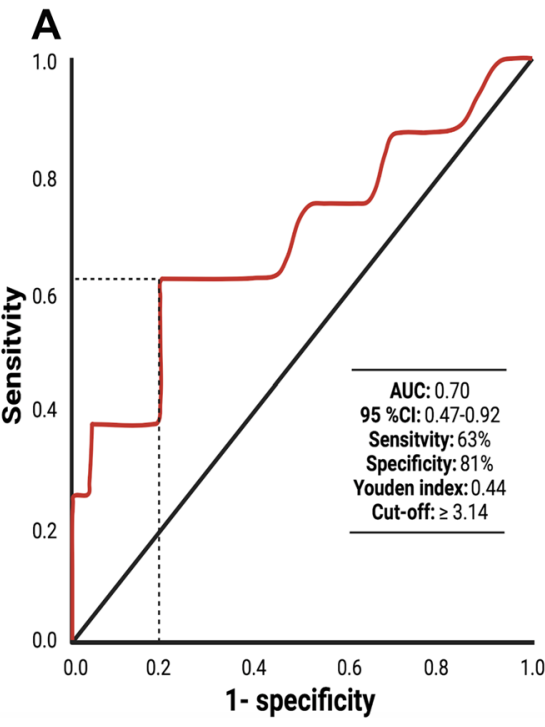

B

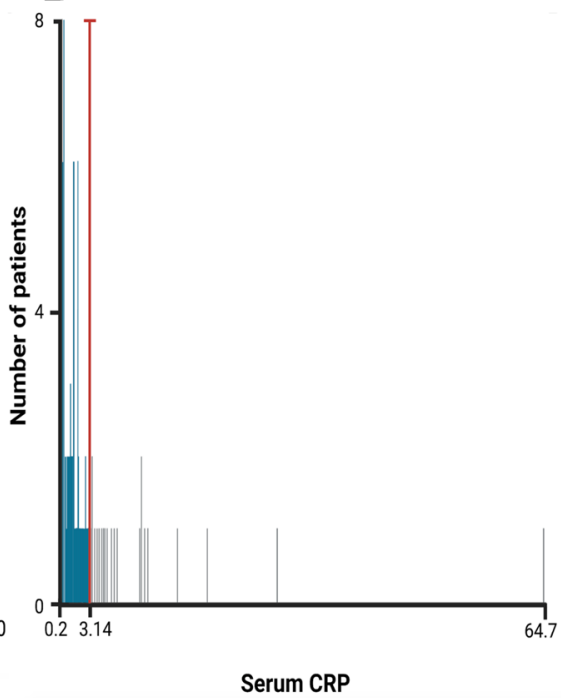

C

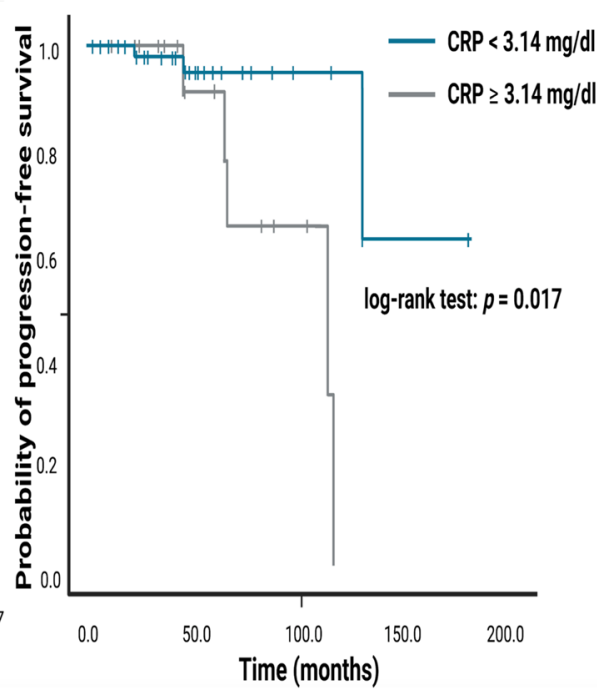

Fig. 2 A Receiver-operating characteristic curve illustrating the ability of baseline serum CRP level to predict tumor progression of vestibular schwannoma. The area under the ROC curve (AUC) of baseline CRP level for tumor progression was 0.70 [95\% confidence interval (CI) 0.47-0.92]. Sensitivity and specificity of baseline CRP level for predicting tumor progression was $63.0 \%$ and $81.0 \%$, respectively, with a threshold of $\geq 3.14 \mathrm{mg} / \mathrm{dl}$. B Frequency distribution histogram for serum CRP levels in the analyzed cohort. Blue and grey bars indicate the number of patients exhibiting normal and high serum CRP levels, respectively. The red line at the junction of two colors displays the optimized cut-off point for serum CRP $(\mathrm{CRP}</ \geq 3.14 \mathrm{mg} / \mathrm{dl})$. C Kaplan-Meier analysis of the tumor progression probability stratified by "normal" CRP $(<3.14 \mathrm{mg} / \mathrm{dl})$ and "high" CRP ( $\geq 3.14 \mathrm{mg} / \mathrm{dl})$. The blue line represents the group of patients with normal CRP levels, whereas the grey line represents the group of patients with elevated CRP levels. Vertical dashes indicate censored data (here: progression-free at last follow-up) in the progression-free survival curves. The time axis is right-censored at 200 months. $p=0.017$ (log-rank test)
Table 1 Patient characteristics and univariate analysis in normal and high CRP level groups (using Fisher's exact test (two-sided) \& independent t-test)

\begin{tabular}{llll}
\hline Characteristics & \multicolumn{2}{l}{ CRP $(\mathrm{n}=87)$} & \\
\cline { 2 - 4 } & $\begin{array}{l}\text { Normal } \\
(<3.14 \mathrm{mg} / \mathrm{dl})\end{array}$ & $\begin{array}{l}\text { High } \\
(\geq 3.14 \mathrm{mg} / \mathrm{dl}) \\
(\mathrm{n}=21)\end{array}$ & $p$-value \\
\hline Sex (female/male) & $34 / 32$ & $13 / 8$ & 0.46 \\
Age $(<60 / \geq 60)$ & $43 / 23$ & $10 / 11$ & 0.62 \\
Smoking $(\geq 10$ cigarettes/d) (yes/no) & $16 / 50$ & $2 / 19$ & 0.22 \\
Obesity (BMI $\geq 30.0)($ yes/no) & $18 / 48$ & $6 / 15$ & 0.99 \\
Connective tissue diseases (yes/no) & $2 / 64$ & $0 / 21$ & 0.99 \\
Diabetes mellitus (yes/no) & $2 / 64$ & $0 / 21$ & 0.99 \\
Karnofsky performance status $(<90 / \geq 90)$ & $18 / 48$ & $6 / 15$ & 0.99 \\
Largest extrameatal tumor diameter (mean \pm SD), mm & $28.16 \pm 9.49$ & $29.26 \pm 10.92$ & 0.66 \\
Tumor size classes $(1 \& 2 / 3)$ & $62 / 4$ & $18 / 3$ & 0.35 \\
Extent of resection $(\mathrm{GTR} / \mathrm{STR})$ & $44 / 22$ & $14 / 7$ & 0.99 \\
MIB-1 labeling index $(<5 \% / \geq 5 \%)$ [available in 83 patients] & $38 / 27$ & $13 / 5$ & 0.41 \\
\hline
\end{tabular}

$B M I$ body mass index; CRP C-reactive protein; GTR gross total resection; $M I B$ molecular immunology borstel; $S D$ standard deviation; $S T R$ subtotal resection

\section{CRP and macrophages}

CD68 and CD 45 staining was performed in 48 and 14 cases, respectively. Positive staining of macrophages by CD68 was observed in $91.7 \%(11 / 12)$ of patients with a CRP $\geq 3.14 \mathrm{mg} / \mathrm{dl}$ and $72.2 \%$ (26/36) of those with a $\mathrm{CRP}<3.14 \mathrm{mg} / \mathrm{dl}$ (Spearman's rank correlation coefficient: $r=0.385, p=0.007)$. Figures $3 \mathrm{~A}$, B show representative histopathological images of CD68-positive macrophage infiltrates within the areas of the tumor in a 


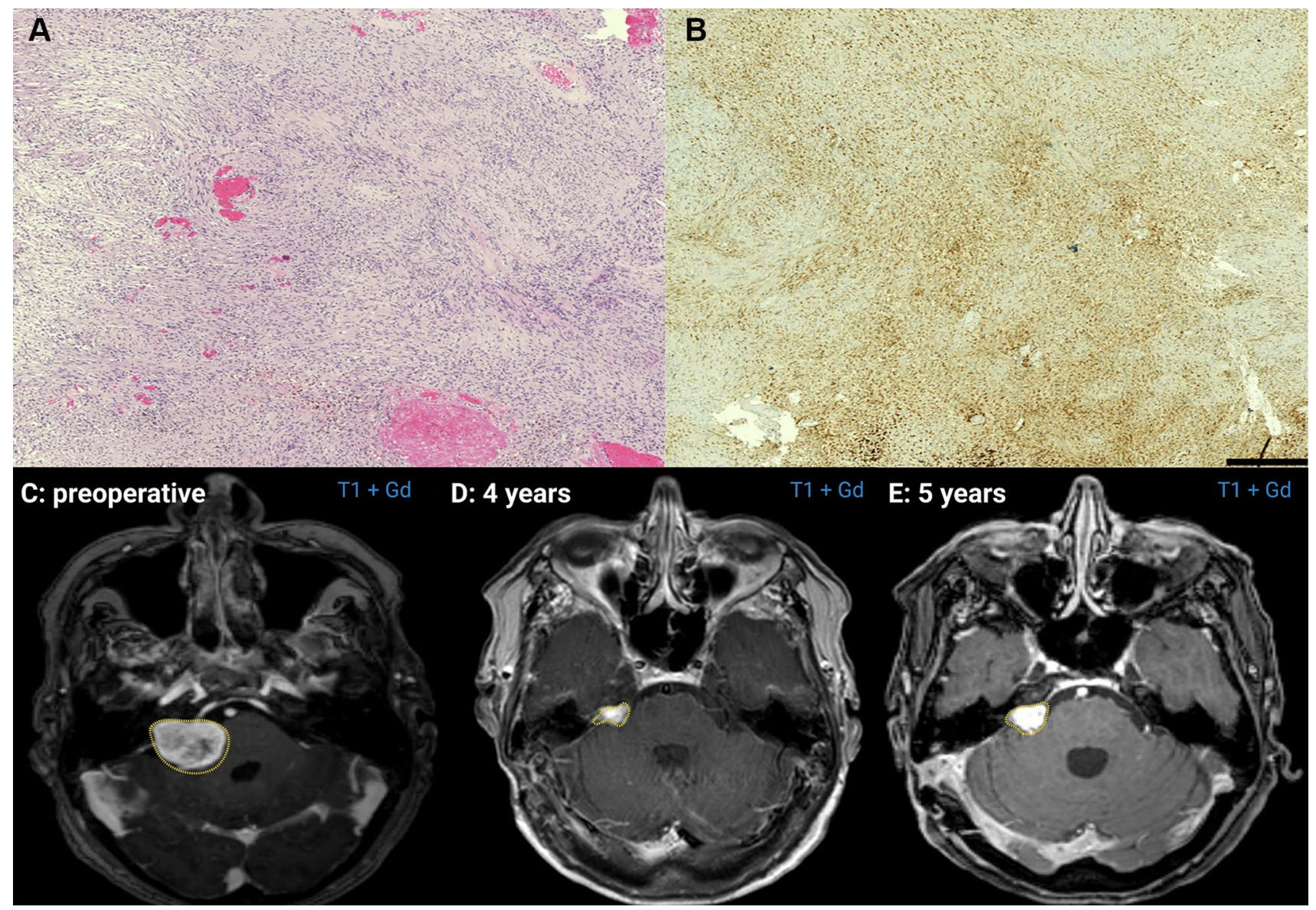

Fig. 3 A Representative neuropathology of a vestibular schwannoma (A hematoxylin \& eosin (H\&E)) showing dense infiltrates of CD68positive macrophages (B CD68; Clone KP1, dilution 1:1000, DAKO, Glastrop, Denmark; bar graph-500 $\mu \mathrm{m})$. C Preoperative Gadolinium (Gd)-enhanced T1-weighted axial MR-image shows a right-sided giant vestibular schwannoma (volume: $16.2 \mathrm{~cm}^{3}$ ) of the same patient as in the neuropathological figures D Gd-enhanced T1-weighted axial

patient who had a recurrence at 5-years after surgery for VS.

\section{Influence of baseline serum CRP levels on progression-free survival}

The mean (range) of imaging follow-up period in the entire cohort was 46.6 (3.0-183.0) months. Eight (9.2\%) patients with tumor progression were identified in the entire cohort. Three $(3 / 66 ; 4.5 \%)$ patients with VS progressions were in the normal CRP level group, whereas $5(5 / 21 ; 23.8 \%)$ were in the high CRP level group. Figures 3C-E display a representative case with gadolinium-enhanced T1-weighted magnetic resonance images revealing a progression of a subtotally resected VS. The mean time of progression-free survival in the entire cohort was 132.5 (95\% CI 106.5-158.4) months. Patients with a normal baseline CRP level $[<3.14 \mathrm{mg} /$
MR-image shows a residual tumor at 4 years after subtotal resection of the right-sided giant vestibular schwannoma (volume: $1.5 \mathrm{~cm}^{3}$ ) $\mathbf{E}$ Gd-enhanced T1-weighted axial MR-image reveals a progress of the residual tumor at 5 years after surgery (volume: $2.0 \mathrm{~cm}^{3}$ ). Volumetric tumor measurements were performed using Brainlab iPlan ${ }^{\circledR}$ software (Brainlab, Feldkirchen, Germany)

dl $(\mathrm{n}=21)]$ had a mean PFS of 159.2 months $(95 \%$ CI 131.8-186.6), whereas patients with an elevated CRP level $[\geq 3.14 \mathrm{mg} / \mathrm{dl}(\mathrm{n}=66)]$ had a mean PFS of 96.1 months (95\% CI 75.1-117.2), respectively (log-rank test: $p=0.017$; Kaplan-Meier curve: Fig. 2C).

\section{Uni- and multivariable Cox regression analysis of progression-free survival}

A univariable Cox regression analysis of PFS was performed for potential predictors of PFS in VS. Subtotal resection and elevated baseline serum CRP $(\geq 3.14 \mathrm{mg} / \mathrm{dl})$ were significantly associated with shortened PFS. We conducted a multivariable Cox regression analysis of PFS considering age $(<60 / \geq 60)$, KPS $(<90 / \geq 90)$, tumor size $(<4 \mathrm{~cm} / \geq 4 \mathrm{~cm})$, extent of resection (GTR/STR), and baseline CRP $(<3.14 / \geq 3.14)$. The multivariable Cox regression analysis 
identified an elevated baseline serum CRP $(\geq 3.14 \mathrm{mg} / \mathrm{dl})$ as a significant and an independent predictor of shortened PFS (Hazard ratio (HR): 7.20, 95\% CI 1.08-48.14, $p=0.04$ ). Table 2 summarizes the uni- and multivariable Cox regression analyses of PFS in VS.

\section{Discussion}

In the present study, we evaluated baseline C-reactive protein levels as a biomarker for progression in sporadic VS patients. We observed significantly decreased progressionfree survival in patients with a high baseline serum CRP $(\geq 3.14 \mathrm{mg} / \mathrm{dl})$ level at the time of VS diagnosis. An elevated CRP level seems to be an independent risk factor for shortened time to tumor progression. Our findings suggest the potential importance of assessing the prognosis of VS by combining clinicopathologic characteristics with the initial systemic inflammatory status.

The rate of progression was $9.2 \%$ in our cohort with a mean (range) follow-up period of 46.6 (3.0-183.0) months. This rate is consistent with previous studies that reported rates of recurrence of $8.8 \%$ or $10.8 \%$ for gross- or subtotally resected VSs [4, 25]. In our cohort, $24.1 \%$ of patients presented with elevated CRP serum concentrations, indicating that increased circulating concentrations of classical inflammatory response elements such as CRP are common among VS patients. The patients who had increased baseline levels of CRP had a significantly shorter time-to-tumor progression than those with CRP levels within the normal range $(<3.14 \mathrm{mg} / \mathrm{dl})$. Lewis et al. [9] suggested that inflammation is a paramount parameter when evaluating the growth of VS. Tumor tissues from eight sporadic VS patients were immunohistochemically investigated and the growing tumors exhibited significantly higher proportions of Ki-67/ Iba1 (ionized calcium-binding adapter molecule)-positive cells and macrophages in their study. This finding was consistent with our previously reported observation that there is a high proportion of $\mathrm{CD}^{+} 8^{+}$macrophages accounting for proliferating cells within VSs [11]. Furthermore, it is known that pro-inflammatory cytokines such as transforming growth factor $\beta 1$, interleukin- $1 \beta$ and interleukin- 6 are significantly overexpressed in human VS compared to normal vestibular nerve samples. Neoplastic Schwann cells were found to produce pro-inflammatory cytokines that might act in an autocrine manner, stimulating cellular proliferation [26]. CRP is a major acute-phase reactant and systemic inflammatory parameter, that is derived mainly from hepatocytes in response to interleukin- 6 and is then secreted into the systemic circulation [27]. Furthermore, CRP was revealed to play a major role in promoting the differentiation of human monocytes towards a proinflammatory classical M1 macrophage [28]. An immunohistochemical analysis of the expression of CD163 and programmed cell death 1 ligand 1 (PD-L1) in 46 sporadic radiation-naïve and subtotally resected VSs elucidated that VS that progressed after surgical resection had higher numbers of M1 macrophages [29]. The increased expression of PD-L1 in progressive VSs was suggested to be the mechanism resulting in the deactivation of tumor-associated macrophages (TAM), growth of the tumor, and the further infiltration of anti-tumor immune cells. Furthermore, paracrine cellular communication between TAMs and Schwann cells seems to explain the decreased anti-tumor effect of TAMs [29]. Additionally, it was demonstrated that intratumoral macrophages contribute significantly to the production of vascular-endothelial-growth-factor (VEGF), which promotes vasodilatation, increases vascular permeability, and induces angiogenesis [30, 31]. VEGF can also act as a chemoattractant for circulating VEGFR-1-expressing macrophages and induces an inflammatory microenvironment [32-35]. Concerning pathophysiology, increased concentrations of CRP might be induced by the autocrine secretion of interleukin-6 in neoplastic Schwann cells, and CRP promotes the differentiation of monocytes toward proinflammatory M1 macrophages, which are predominant in VS tissue and drive the growth of the tumor through paracrine communication between Schwann cells and TAMs. This potential
Table 2 Uni- and multivariate Cox regression analysis of progression-free survival in vestibular schwannoma

\begin{tabular}{|c|c|c|c|c|c|c|}
\hline \multirow[t]{2}{*}{ Variable } & \multicolumn{3}{|c|}{ Univariate } & \multicolumn{3}{|c|}{ Multivariate } \\
\hline & HR & $95 \% \mathrm{CI}$ & $p$-value & HR & $95 \% \mathrm{CI}$ & $p$-value \\
\hline Age $(<60$ vs. $\geq 60)$ & 2.47 & $0.58-10.50$ & 0.22 & 1.65 & $0.26-10.33$ & 0.59 \\
\hline $\mathrm{CRP}(<3.14 \mathrm{mg} / \mathrm{dl} \mathrm{vs} . \geq 3.14 \mathrm{mg} / \mathrm{dl})$ & 6.05 & $1.15-31.95$ & 0.03 & 7.20 & $1.08-48.1$ & 0.04 \\
\hline Tumor size classes (small \& medium vs. large) & 3.79 & $0.71-20.08$ & 0.12 & 2.23 & $0.14-36.65$ & 0.57 \\
\hline Extent of resection (STR vs. GTR) & 4.90 & $1.13-21.18$ & 0.03 & 6.71 & $0.85-52.8$ & 0.07 \\
\hline Karnofsky performance status (<90 vs. $\geq 90$ ) & 1.04 & $0.23-4.66$ & 0.96 & 1.22 & $0.18-8.09$ & 0.84 \\
\hline Sex (female vs. male) & 1.76 & $0.40-7.67$ & 0.45 & & & \\
\hline MIB-1 labeling index (<5\% vs. $\geq 5 \%$ ) & 2.24 & $0.49-10.18$ & 0.30 & & & \\
\hline
\end{tabular}

$C I$ confidence interval; $C R P$ C-reactive protein; GTR gross total resection; $H R$ hazard ratio; $M I B$ molecular immunology borstel; STR subtotal resection 
pathophysiological pathway might be associated with our finding that the baseline serum CRP levels significantly correlated with the proportion of $\mathrm{CD} 68^{+}$macrophages.

The baseline determination of serum CRP seems to be useful to identify a subgroup of patients who might be predisposed to early tumor progression. There are some potential implications for future investigations and the clinical care of those patients. Lewis et al. [9] showed that growing VSs that express the PK11195 target translocator protein in macrophages within the tumor tissue can be detected by PET imaging using the tracer ${ }^{11} \mathrm{C}-(\mathrm{R})-\mathrm{PK} 11195$. Therefore, patients presenting with increased serum levels of CRP might benefit from preoperative or follow-up PET imaging examinations to predict tumor progression and set individualized follow-up imaging intervals. In addition to the diagnostic potential of using PET imaging for VS patients with increased CRP concentrations, future therapeutic approaches for an individualized therapy might benefit from an inexpensive and fast identification of a subgroup of patients who are at risk of tumor progression due to the inflammatory microenvironment via a baseline CRP determination. To date, the anti-VEGF antibody bevacizumab is the only targeted molecular treatment in clinical use for VSs [36, 37]. However, its application and use are only proven for neurofibromatosis type 2 , and recent concerns have been raised regarding the use of bevacizumab due to potential cardiovascular and renal complications [38, 39].

Moreover, future trials have to elucidate if those patients having increased serum CRP levels will benefit from early stereotactic radiosurgery in case of residual or progressive tumor. This potential clinical implication has not been addressed so far. Lewis et al. [40] investigated the changes of the vestibular schwannoma microenvironment in patients who underwent stereotactic radiosurgery using multinuclear MRI. They suggested that patients who showed a well response to stereotactic radiosurgery and tumor growth attenuation following stereotactic radiosurgery had a reduced vascular supply of the vestibular schwannoma and a reduced amount of pro-tumoral TAM infiltrates in the tumor microenvironment. Hence, this interesting hypothesis might emphasize that patients with an increased serum CRP in combination with a high density of macrophage infiltrates might benefit from an early stereotactic radiosurgery due to the reduction of vascular supply and decreased infiltration of pro-tumoral TAMs. However, future trials will have to investigate this hypothesis in a thorough study design using imaging methods such as dynamic contrast-enhanced (DCE)-MRI or PET tracers reflecting the inflammatory burden in the absence of resected tissue for histopathological analysis during or after adjuvant stereotactic radiosurgery $[9,10]$.

COX-2 expression was found to be significantly associated with higher MIB-1 expression [12]. COX-2-inhibiting drugs such as salicylates can be a potential treatment option for VS patients with increased systemic inflammatory parameters. In vitro and clinical findings suggested that aspirin has a cytostatic effect, and VS patients taking aspirin demonstrated reduced tumor growth [13]. In contrast, a retrospective analysis of 1048 patients showed that the intake of acetylsalicylic acid, non-steroidal anti-inflammatory drugs, glucocorticoids and other immunosuppressants did not result in differences in COX-2 or MIB-1 expression [12]. However, it is unlikely that the dosage of $100 \mathrm{mg}$, which is used in Germany and many other countries, can sustain an antiplatelet effect and has an impact on COX-2 because the antiproliferative regulation is based on a transcriptional level and is not regulated by the acetylation of the amino acid serine residue within the enzyme COX-2 [41, 42]. An ongoing prospective phase II, double-blind longitudinal and randomized trial is currently recruiting VS patients to investigate aspirin (administered $325 \mathrm{mg}$ twice daily) intake regarding the tumor growth inhibition (clinical trial number: NCT03079999). This trial might clarify the potential role of acetylsalicylic acid as an antiproliferative treatment option for sporadic VS patients.

\section{Limitations}

The retrospective analysis of clinical data is the major limitation of the present study. Moreover, during this study, which investigated patients in a time period from 2001 to 2020, MRI quality improved significantly, which might have influenced the analysis of PFS. However, we applied highly selective inclusion criteria, such as the analysis of patients who have sporadic VSs, underwent surgical resection for VS at initial diagnosis only, and did not receive any kind of radiation therapy before or after surgery, to achieve a reliable analysis in a homogeneous cohort. Furthermore, baseline CRP values, histopathological reports, and imaging data at presentation and follow-up, which were used as the main data records were extracted from a computerized hospital information system and therefore not affected by the retrospective design.

\section{Conclusions}

Baseline serum CRP level is a potential prognostic marker that can independently predict progression-free survival in VS. Our investigation emphasizes the need for further studies evaluating the role of inflammation in the prognosis of VS.

Supplementary Information The online version contains supplementary material available at https://doi.org/10.1007/s11060-021-03918-0. 
Acknowledgements The graphical abstract was created using BioRender

Author contributions Data acquisition: JW data interpretation: EG, and JW; writing: JW, and EG; Statistical analysis: EG, JW, and JW; proof reading: AG, PS, UH, VB, CC, HV, MT, MS, AB, MH, and EG.

Funding Open Access funding enabled and organized by Projekt DEAL. Not applicable.

Data availability Research data will not be shared.

Code availability Not applicable.

\section{Declarations}

Conflict of interest The authors declare no conflict of interests.

Ethical approval This study was performed in line with the principles of the Declaration of Helsinki. Approval was granted by the Ethics Committee of the University of Bonn (228/2021).

Open Access This article is licensed under a Creative Commons Attribution 4.0 International License, which permits use, sharing, adaptation, distribution and reproduction in any medium or format, as long as you give appropriate credit to the original author(s) and the source, provide a link to the Creative Commons licence, and indicate if changes were made. The images or other third party material in this article are included in the article's Creative Commons licence, unless indicated otherwise in a credit line to the material. If material is not included in the article's Creative Commons licence and your intended use is not permitted by statutory regulation or exceeds the permitted use, you will need to obtain permission directly from the copyright holder. To view a copy of this licence, visit http://creativecommons.org/licenses/by/4.0/.

\section{References}

1. Ammar MB, Piccirillo E, Topsakal V, Taibah A, Sanna M (2012) Surgical results and technical refinements in translabyrinthine excision of vestibular schwannomas: the Gruppo Otologico experience. Neurosurgery 70:1481-1491. https://doi.org/ 10.1227/NEU.0b013e31824c010f

2. Samii M, Gerganov VM, Samii A (2010) Functional outcome after complete surgical removal of giant vestibular schwannomas. J Neurosurg 112:860-867. https://doi.org/10.3171/2009.7. JNS0989

3. Iwai Y, Ishibashi K, Watanabe Y, Uemura G, Yamanaka K (2015) Functional preservation after planned partial resection followed by gamma knife radiosurgery for large vestibular schwannomas. World Neurosurg 84:292-300. https://doi.org/ 10.1016/j.wneu.2015.03.012

4. Sughrue ME, Kaur R, Rutkowski MJ et al (2011) Extent of resection and the long-term durability of vestibular schwannoma surgery. J Neurosurg 114:1218-1223. https://doi.org/10.3171/ 2010.11.JNS10257

5. Kondziolka D, Mousavi SH, Kano H, Flickinger JC, Lunsford LD (2012) The newly diagnosed verstibular schwannoma: radiosurgery, resection, or observation? Neurosurg Focus 33(3):E8. https://doi.org/10.3171/2012.6.FOCUS12192

6. Chen Z, Prasad SC, Di Lella F et al (2014) The behavior of residual tumors and facial nerve outcomes after incomplete excision of vestibular schwannomas. J Neurosurg 120:12781287. https://doi.org/10.3171/2014.2.JNS131497

7. Coussens LM, Werb Z (2002) Inflammation and cancer. Nature 420:860-867. https://doi.org/10.1038/nature01322

8. Roxburgh CS, McMillan DC (2010) Role of systemic inflammatory response in predicting survival in patients with primary operable cancer. Future Oncol 6:149-163. https://doi.org/10. 2217/fon.09.136

9. Lewis D, Roncaroli F, Agushi E et al (2019) Inflammation and vascular permeability correlate with growth in sporadic vestibular schwannoma. Neuro Oncol 21:314-325. https://doi.org/10. 1093/neuonc/noy177

10. Hannan CJ, Lewis D, O’Leary C, et al (2020) The inflammatory microenvironment in vestibular schwannoma. Neurooncol Adv 2(1):vdaa23. https://doi.org/10.1093/noajnI/vdaa023

11. Wach J, Brandecker S, Güresir Á, Schuss P, Vatter H, Güresir E (2020) The impact of the MIB-1 index on facial nerve outcomes in vestibular schwannoma surgery. Acta Neurochir 162(5):1205-1213. https://doi.org/10.1007/s00701-020-04283-z

12. Behling F, Ries V, Skardelly M et al (2019) COX2 expression is associated with proliferation and tumor extension in vestibular schwannoma but is not influenced by acetylsalicylic acid intake. Acta Neuropathol Commun 7:105. https://doi.org/10. 1186/s40478-019-0760-0

13. Dilwali S, Kao SY, Fujita T, Landegger LD, Stankovic KM (2015) Nonsteroidal anti-inflammatory medications are cytostatic against human vestibular schwannomas. Transl Res 166(1):1-11. https://doi.org/10.1016/j.trsl.2014.12.007

14. Yoshimoto Y (2005) Systematic review of the natural history of vestibular schwannoma. J Neurosurg 103:59-63. https://doi. org/10.3171/jns.2005.103.1.0059

15. Agrawal Y, Clark JH, Limb CJ, Niparko JK, Francis HW (2010) Predictors of vestibular schwannoma growth and clinical implications. Otol Neurotol 31:807-812. https://doi.org/10.1097/ MAO.0b013e3181de46ae

16. Shrotriya S, Walsh D, Bennani-Baiti N, Thomas S, Lorton C (2015) C-reactive protein is an important biomarker for prognosis tumor recurrence and treatment response in adult solid tumors: a systematic review. PLoS ONE 10(12):e0143080. https://doi.org/10.1371/journal.pone.0143080

17. Kliesch S, Vogelgesang S, Benecke R, Horstmann GA, Schroeder HWS (2010) Malignant brain oedema after radiosurgery of a medium-sized vestibular schwannoma. Cent Eur Neurosurg 71(2):88-91. https://doi.org/10.1055/s-0029-12427 28

18. Rosahl S, Bohr C, Lell M, Hamm K, Iro H (2017) Diagnostics and therapy of vestibular schwannomas-an interdisciplinary challenge. GMS Curr Top Otorhinolaryngol Head Neck Surg 16:Doc03. https://doi.org/10.3205/cto000142

19. Gormley WB, Sekhar LN, Wright DC, Kamerer D, Schessel D (1997) Acoustic neuromas: results of current surgical management. Neurosurgery 41:50-58. https://doi.org/10.1097/00006123199707000-00012

20. Fukuda M, Oishi M, Hiraishi T, Natsumeda M, Fujii Y (2011) Clinicopathological factors related to regrowth of vestibular schwannoma after incomplete resection. J Neurosurg 114:12241231. https://doi.org/10.3171/2020.11.JNS101041

21. Lees KA, Tombers NM, Link MJ et al (2018) Natural history of sporadic vestibular schwannoma: a volumetric study of tumor growth. Otolaryngol Head Neck Surg 159(3):535-542. https://doi. org/10.1177/0194599818770413 
22. van de Langenberg R, de Bondt BJ, Nelemans PJ, Baumert BG, Stokroos RJ (2009) Follow-up assessment of vestibular schwannomas: volume quantification versus two-dimensional measurements. Neuroradiology 51(8):517-524. https://doi.org/10.1007/ s00234-009-0529-4

23. Mazumdar M, Glassman JR (2000) Categorizing a prognostic variable: review of methods, code for easy implementation and applications to decision-making about cancer treatments. Stat Med 19(1):113-132

24. Heagerty PJ, Lumley T, Pepe MS (2000) Time-dependent ROC curves for censored survival data and a diagnostic marker. Biometrics 56(2):337-344. https://doi.org/10.1111/j.0006-341x.2000. 00337.x

25. Syed MI, Wolf A, Ilan O et al (2017) The behaviour of residual tumour after the intentional incomplete excision of a vestibular schwannoma: is it such a bad thing to leave some behind? Clin Otolaryngol 42:92-97. https://doi.org/10.1111/coa.12670

26. Taurone S, Bianchi E, Attanasio G et al (2015) Immunohistochemical profile of cytokines and growth factors expressed in vestibular schwannoma and in normal vestibular nerve tissue. Mol Med Rep 12(1):737-745. https://doi.org/10.3892/mmr.2015.3415

27. Rattazzi M, Puato M, Faggin E et al (2003) C-reactive protein and interleukin-6 in vascular disease: culpritis or passive bystanders? J Hypertens 21(10):1787-1803. https://doi.org/10.1097/00004872200310000-00002

28. Devaraj S, Jialal I (2011) C-reactive protein polarizes human macrophages to an $\mathrm{M} 1$ phenotype and inhibits transformation to the M2 phenotype. Arterioscler Thromb Vasc Biol 31(6):1397-1402. https://doi.org/10.1161/ATVBAHA.111.225508

29. Perry A, Graffeo CS, Carlstrom LP et al (2019) Predominance of M1 subtype among tumor-associated macrophages in phenotypically aggressive sporadic vestibular schwannoma. J Neurosurg 4:1-9. https://doi.org/10.3171/2019.7.JNS19879

30. Lewis D, Donofrio CA, O'Leary C et al (2020) The microenvironment in sporadic and neurofibromatosis type II-related vestibular schwannoma: the same tumor or different? A comparative imaging and neuropathology study. J Neurosurg 29:1-11. https://doi.org/ 10.3171/2020.3.JNS193230

31. Cayé-Thomasen P, Werther K, Nalla A et al (2005) VEGF and VEGF receptor-1 concentration in vestibular schwannoma homogenates correlates to tumor growth rate. Otol Neurotol 26(1):98-101. https://doi.org/10.1097/00129492-20050 1000-00017

32. Ferrara N, Gerber HP, LeCouter J (2003) The biology of VEGF and its receptors. Nat Med 9(6):669-676. https://doi.org/10.1038/ nm0603-669

33. Weddell JC, Chen S, Imoukhuede PI (2017) VEGFR1 promotes cell migration and proliferation through PLC $\gamma$ and PI3K pathways. NPJ Syst Biol 4(1):1. https://doi.org/10.1038/s41540-017-0037-9
34. Freire Valls A, Knipper K, Giannakouri E et al (2019) VEGFR1+ metastasis-associated macrophages contribute to metastatic angiogenesis and influence colorectal cancer patient outcome. Clin Cancer Res 25(18):5674-5685. https://doi.org/10.1158/1078-0432. CCR-18-2123

35. Kerber M, Reiss Y, Wickersheim A et al (2008) Flt-1 signaling in macrophages promotes glioma growth in vivo. Cancer Res 68(18):7342-7351. https://doi.org/10.1158/0008-5472. CAN-07-6241

36. Plotkin SR, Merker VL, Halpin C et al (2012) Bevacizumab for progressive vestibular schwannoma in neurofibromatosis type 2: a retrospective review of 31 patients. Otol Neurotol 33(6):10461052. https://doi.org/10.1097/MAO.0b013e31825e73f5

37. Plotkin SR, Stemmer-Rachamimov AO, Barker FG 2nd et al (2009) Hearing improvement after bevacizumab in patients with neurofibromatosis type 2. N Engl J Med 361(4):358-367. https:// doi.org/10.1056/NEJMoa0902579

38. Blakeley JO, Evans DG, Adler J et al (2012) Consensus recommendations for current treatments and accelerating clinical trials for patients with neurofibromatosis type 2. Am J Med Genet A 158A(1):24-41. https://doi.org/10.1002/ajmg.a.34359

39. Mautner VF, Nguyen R, Knecht R, Bokemeyer C (2010) Radiographic regression of vestibular schwannomas induced by bevacizumab treatment: sustain under continuous drug application and rebound after drug discontinuation. Ann Oncol 21(11):22942295. https://doi.org/10.1093/annonc/mdq566

40. Lewis D, McHugh DJ, Li KL, Zhu X, Mcbain C, Lloyd SK, Jackson A, Pathmanaban ON, King AT, Coope DJ (2021) Detection of early changes in the post-radiosurgery vestibular schwannoma microenvironment using multinuclear MRI. Sci Rep 11(1):15712

41. Wu KK (2003) Control of COX-2 and iNOS gene expression by aspirin and salicylate. Thromb Res 110(5-6):273-276. https://doi. org/10.1016/s0049-3848(03)00412-2

42. Xu XM, Sansores-Garcia L, Chen XM, Matjevic-Aleksic N, Du M, Wu KK (1999) Suppression of inducible cyclooxygenase 2 gene transcription by aspirin and sodium salicylate. Proc Natl Acad Sci USA 96(9):5292-5297. https://doi.org/10.1073/pnas. 96.9.5292

Publisher's Note Springer Nature remains neutral with regard to jurisdictional claims in published maps and institutional affiliations. 